\title{
Left Hypochondriac Region
}

National Cancer Institute

\section{Source}

National Cancer Institute. Left Hypochondriac Region. NCI Thesaurus. Code C32961.

The area under the left costal marg in of the ribs. 